ORIGINAL ARTICLE

\title{
Autophagy Protects from Ventilator-induced Lung Injury Partly through Activation of Haem Oxygenase-1 Pathway
}

\author{
D Liu, Y Yang, Y Qi, K Wu, S Zhao
}

\begin{abstract}
Mechanical ventilation is an indispensable life supportive treatment in the intensive care unit (ICU) for the critically ill patients with acute lung injury (ALI) or acute respiratory distress syndrome (ARDS). But longer ventilation time has been proven to contribute to the lung injury and has been recognized as ventilator-induced lung injury (VILI). Recent studies have suggested that haem oxygenase-1 (HO-1) signalling pathways $m$ ay play a critical role in the process of inflam $m$ ationand autophagy, and autophagy can reduce the damage of VILI partly by activating the HO-1 pathways. Thus, we propose that autophagy, partly through activation of HO-1 pathway, may protect from VILI, which might be a new potential therapeutic target. Although the exact mechanism of autophagy and its exact role in the VILI need to be further explored, at least it provides a potential target in the future prevention of VILI.
\end{abstract}

Keywords: Autophagy, haem oxygenase-1 (HO-1) pathway, ventilator-induced lung injury

WIMJ Open 2014; 1 (2): 35

\section{INTRODUCTION}

Mechanical ventilation is an indispensable life supportive treatment in the intensive care unit (ICU) for the critically ill patients with acute lung injury (ALI) or acute respiratory distress syndrome [ARDS] (1). However, longer ventilation time may initiate or exacerbate lung damage in both healthy and diseased lungs, which is called ventilator-induced lung injury [VILI] (2). Both traditional high tidal volume ventilation and low tidal volume cannot completely avoid regional alveolar distension for the highly spatial heterogeneity in the lungs of ALI/ARDS (3). Because these complications may have potential relationships in patients subjected to mechanical ventilation, it is very necessary to find a potential treatment strategy to further eliminate or alleviate VILI in the ICU.

Autophagy is a highly-conserved eukaryotic cellular recycling process to degrade the cytoplasmic components, such as damaged organelles, long-lived proteins and other macromolecules (4). Autophagy was originally recognized as a crucial pro-survival mechanism to supply the cell with nutrients under unfavourable grown conditions (5). How-

From: Department of Thoracic Surgery, First Affiliated Hospital of Zhengzhou University, Zhengzhou, China.

Correspondence: Dr S Zhao, Department of Thoracic Surgery, First Affiliated Hospital, Zhengzhou University, Zhengzhou, 450052, China.

E-mail: zhaosong@zzu.edu.cn ever, it is still unclear if autophagy promotes cell survival during stress or induces autophagic cell death, which is often termed as type II programmed cell death. Therefore, there is still no consensus about the exact role of autophagy on cell survival or death. We speculate that autophagy, partly through activation of haem oxygenase-1 system (HO-1), may protect from VILI. Our view suggests that inhibition of autophagy may be a possible therapeutic modality for VILI in the ICU.

\section{BACKGROUND AND EVIDENCE}

Recently, several reports have indicated that autophagy can be induced during many different situations, such as energy starvation, inflammation, cancer and other diseases (6). Moreover, it is reported that autophagy can clear the cellular components, such as inflammasomes and cytokines, thus providing an important means of regulating inflammation (7). It is reported that HO-1 upregulation by haemin may play a protective role in ventilator-induced lung injury by suppression of inflammatory process and oxidative stress (8), which is one of the major regulation pathways of autophagy (9), thus there is no doubt that autophagy can be activated after VILI.

In fact, many reports have suggested that HO-1 signalling pathways have an important role in the regulation of autophagy (10) and inflammation (11). In the C57BL/6 mice model, HO-1-mediated autophagy can protect against 
hepatocyte cell death and hepatic injury from infection/sepsis in mice (12). Moreover, in myocardial dysfunction, HO-1 can prevent cardiac dysfunction in streptozotocin-diabetic mice by reducing inflammation, oxidative stress, apoptosis and enhancing autophagy (13). Furthermore, in the C57BL/6N mice, sevoflurane can attenuate pulmonary inflammation and ventilator-induced lung injury by upregulation of HO-1 mRNA expression in mice (14). In other experiments, impairment of autophagy results in an ameliorated inflammatory response to mechanical ventilation and decreases lung injury in the mice lacking autophagin1/ATG4B (15). Thus, the above reports have shown that autophagy activated during VIL I may be essential for the protection regulated by the HO-1 pathway.

These studies have suggested that autophagy can act as a survival pathway in the process of inflammation against VILI. Previous studies have proven that HO-1 pathway, one of the main regulators in autophagy, can decrease VILI through inhibiting the inflammatory process and oxidative stress $(8,16)$. Thus, we speculate that autophagy may play a role as a survival pathway during the VILI through the regulation of inflammatory response.

\section{CONCLUSION}

In recent years, the effect of autophagy during VILI has been explored extensively. The exact role of autophagy and its mechanism in the VILI should be further investigated. At least it provides possible therapeutic foci in the future prevention of VILI in the ICU.

\section{ACKNOWLEDGMENTS}

This study was supported by the Youth Innovation Fund Project of the First Affiliated Hospital of Zhengzhou University. The authors declare that they have no conflict of interest in any matter related to this work.

\section{REFERENCES}

1. Tremblay LN, Slutsky AS. Ventilator-induced lung injury: from the bench to the bedside. Intensive Care Med 2006; 32: 24-33.

2. Kuipers MT, van der Poll T, Schultz MJ, Wieland CW. Bench-tobedside review: damage-associated molecular patterns in the onset of ventilator-induced lung injury. Crit Care 2011; 15: 235. doi: 10.1186/ cc10437. Epub 2011 Nov 30.

3. Mertens M, Tabuchi A, Meissner S, Krueger A, Schirrmann K, Kertzscher $U$ et al. Alveolar dynamics in acute lung injury: heterogeneous distension rather than cyclic opening and collapse. Crit Care Med 2009; 37: 2604-11. doi: 10.1097/CCM.0b013e3181a5544d.

4. Wu WK, Coffelt SB, Cho CH, Wang XJ, Lee CW, Chan FK et al. The autophagic paradox in cancer therapy. Oncogene 2012; 31: 939-53. doi: 10.1038/onc.2011.295. Epub 2011 Jul 18.
5. Mizushima N, Levine B, Cuervo AM, Klionsky DJ. Autophagy fights disease through cellular self-digestion. Nature 2008; 451: 1069-75. doi: 10.1038/nature06639.

6. Rosenfeldt MT, Ryan KM. The multiple roles of autophagy in cancer. Carcinogenesis 2011; 32: 955-63. doi: 10.1093/carcin/bgr031. Epub 2011 Feb 11.

7. Jones SA, Mills KH, Harris J. Autophagy and inflammatory diseases. Immunol Cell Biol 2013; 91: 250-8. doi: 10.1038/icb.2012.82. Epub 2013 Jan 15.

8. An L, Liu CT, Qin XB, Liu QH, Liu Y, Yu SY. Protective effects of hemin in an experimental model of ventilator-induced lung injury. Eur J Pharmacol 2011; 661: 102-8. doi: 10.1016/j.ejphar.2011.04.032. Epub 2011 Apr 28.

9. Ryter SW, Choi AM. Regulation of autophagy in oxygen-dependent cellular stress. Curr Pharm Des 2013; 19: 2747-56.

10. Motterlini R, Foresti R. Heme oxygenase- 1 as a target for drug discovery. Antioxid Redox Signal 2014; 20: 1810-26. doi: 10.1089/ ars.2013.5658. Epub 2014 Feb 28.

11. Yun N, Cho HI, Lee SM. Impaired autophagy contributes to hepatocellular damage during ischemia/reperfusion: heme oxygenase-1 as a possible regulator. Free Radic Biol Med 2014; 68: 168-77. doi: 10.1016/j.freeradbiomed.2013.12.014. Epub 2013 Dec 22.

12. Carchman EH, Rao J, Loughran PA, Rosengart MR, Zuckerbraun BS. Heme oxygenase-1-mediated autophagy protects against hepatocyte cell death and hepatic injury from infection/sepsis in mice. Hepatology 2011; 53: 2053-62. doi: 10.1002/hep.24324. Epub 2011 May 2.

13. Zhao Y, Zhang L, Qiao Y, Zhou X, Wu G, Wang L et al. Heme oxygenase-1 prevents cardiac dysfunction in streptozotocin-diabetic mice by reducing inflammation, oxidative stress, apoptosis and enhancing autophagy. PLoS One 2013; 8: e75927. doi: 10.1371/ journal.pone.0075927. eCollection 2013.

14. Xiong XQ, Lin LN, Wang LR, Jin LD. Sevoflurane attenuates pulmonary inflammation and ventilator-induced lung injury by upregulation of HO-1 mRNA expression in mice. Int $\mathrm{J}$ Nanomedicine 2013; 6: 1075-81. doi: 10.2147/IJN.S41625. Epub 2013 Mar 13.

15. López-Alonso I, Aguirre A, González-López A, Fernández ÁF, AmadoRodríguez L, Astudillo A et al. Impairment of autophagy decreases ventilator- induced lung injury by blockade of the NF- $\kappa$ B pathway. Am J Physiol Lung Cell Mol Physiol 2013; 304: L844-52. doi: 10.1152/ajplung.00422.2012. Epub 2013 Apr 12.

16. An L, Liu CT, Yu MJ, Chen ZH, Guo XG, Peng-Wang et al. Heme oxygenase-1 system, inflammation and ventilator-induced lung injury. Eur J Pharmacol 2012; 677: 1-4. doi: 10.1016/j.ejphar.2011.12.010. Epub 2011 Dec 16.

Submitted 10 Mar 2014

Accepted 27 Mar 2014

Published 12 May 2014

Online: http://myspot.mona.uwi.edu/wimjopen/article/66

(C) Liu et al 2014.

This is an open access article made freely available under Creative Commons Attribution 4.0 International (CC BY 4.0). Users are free to share, copy and adapt this work as long as the copyright holder (author) is appropriately and correctly credited. See http://creativecommons.org/ licences/by/4.0/deed.en_us for more information. 